\title{
Control of Grid Connected Three-Phase Inverter for Hybrid Renewable Systems using Sliding Mode Controller
}

\author{
Sami Younsi \\ Technical College at Dammam - KSA \\ Technical and Vocational Training Corporation
}

\author{
Nejib Hamrouni \\ Laboratory of Analysis and Treatment of Energetic and \\ Electric Systems (ATEES) \\ Science Faculty of Tunis-University of Tunis El Manar
}

\begin{abstract}
This paper presents a power control approach of a grid connected 3-phase inverter for hybrid renewable energy systems that consists of wind generator, flywheel energy storage system and diesel generator. A sliding controller is developed around the grid connected inverter to control the injected currents which leads to control the active and reactive powers requested by grid and/or isolated loads. In series with the controller, a Space Vector Pulse width Modulation method is used to drive the six inverter switches to generate 3-phase voltages and currents for transferring the desired powers requested by the alternative side. Simulations under MatlabSimulink software of the hybrid renewable energy systems are made to show performances given by the developed sliding mode controller.
\end{abstract}

Keywords-Grid connected systems; sliding controller; hybrid renewable systems; SVPWM

\section{INTRODUCTION}

The international renewable energy program is a strategic initiative for the world that aims to substantially increase the share of renewable energy in the total energy mix. In 2017, worldwide, renewable power capacity had a $31 \%$ share of total power capacity, edging out coal [1]. In terms of total power output, renewable energy is predicted to make $28 \%$ of global electricity output by 2021[1]. This strategy is followed after the reduction of fossil fuel sources such as oil and gas. There are many renewable sources of energy such us wind energy, solar energy, and biomass. They appear clearly to complete the used energy. Their production fluctuates and it is not predictable $[2,3,4]$. These problems affect directly the quality of the active and reactive power transferred to the grid which are very fluctuating and which pose unbalances consumptionproduction. This limits their rate of penetration into the grid $[5,6]$.

These problems of the grid connection and the quality of the energy transmitted can be solved by the good control of the active and reactive powers transferred from the renewable sources. This control is possible by the action on the inverter which is the principle element of connection between renewable sources and the grid. There are many researches who worked on the control of active and reactive powers generated by renewable wind, solar and hybrid energy systems and they have used various methods $[7,8]$.
In this paper we present the active and reactive powers control for a 3-phase grid connected inverter of hybrid renewable energy system (HRES) that consist of wind system, flywheel energy storage system and diesel generator. A sliding mode controller is developed from the mathematic line model to control the injected currents which leads to control the active and reactive powers requested by grid and/or isolated loads. This method has been used in many works with wind and solar renewable energy systems generally to extract the maximum power (MPPT)[9], to control the grid connected photovoltaic system [10] and to control the electrical machines in wind energy systems[2,3,11]. In series with the sliding controller a Space Vector Pulse Width Modulation (SVPWM) method is used to drive the six inverter switches which generate consequently the necessary 3-phases voltages and currents for transferring the powers requested by the grid. This method is developed in this paper because it is easy to implement on the calculator and it can eliminate the low order harmonics generated by the inverter. The experiment results of the SVPWM show the high reliability of this method. Simulations under Matlab-Simulink software are made to show the results given by the developed sliding mode controller. These results show the advantages of this controller that offers a compromise between good speed of system response and reliability, especially since the system is very fluctuating in very short time depending on the wind speed.

This paper is organized as follows. Section II describes the HRES configuration. Section III presents the control approach within the sliding controller. Section IV presents the simulation results and discussions.

\section{SYSTEM COMPONENTS AND DESCRIPTION}

The simplest structure of the hybrid renewable energy system that studied is shown on figure 1. It consists of power electronic converters which increase the system efficiency and simplify the control methods. This configuration based on permanent magnetic synchronous machine (PMSM) offers a good efficiency for low power $[2,3,4]$. The AC/DC converters are used to connect hybrid system with the DC-link. It is a bidirectional converter, to allow the energy transfer between the DC-link and the flywheel in the two directions. The DC-link and the AC grid are connected by capacitor and 3 phase 
inverter. An RL filter can be also added to smooth the current. Salient parameters of the system are presented in table 1 .

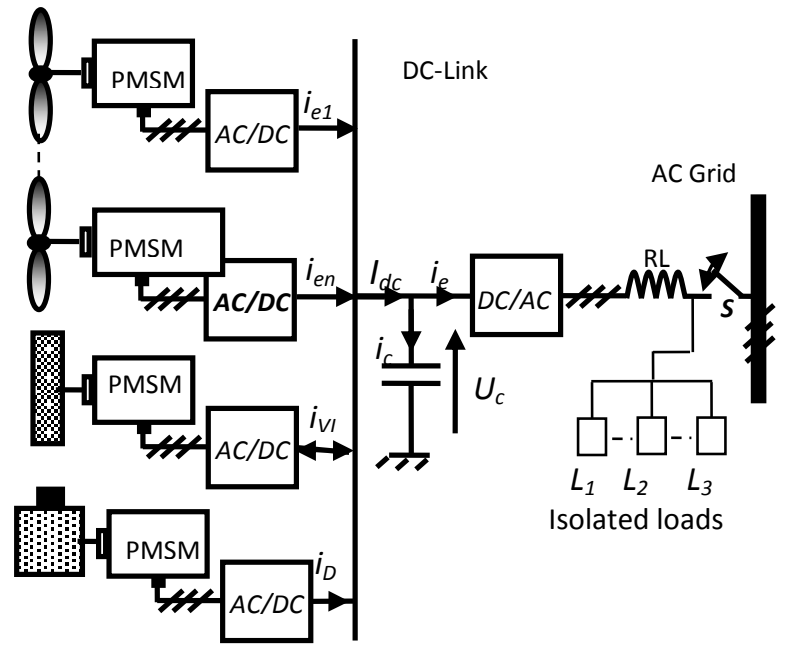

Fig. 1. The Grid Connected Hybrid System Configuration.

\section{CONTROL STRATEGY}

In our previous works [2,3] we have developed local methods to control subsystems of the overall HRES and a global supervisor able to generate the reference powers requested by the grid. The aim of this paper is to control, by sliding controller, the 3-phase inverter which connects the DC-link bus to the grid.

The control of active and reactive powers transferred to the grid is carried out by the control of grid injected currents. The control vector $U=\left[\begin{array}{ll}V_{o d_{-} r e f} & V_{o q_{-} r e f}\end{array}\right]^{T}$ that represents the output reference voltages of the inverter in Park-dq axis is calculated by sliding mode method for current control. The reference values of currents are calculated by using the active and reactive powers reference values $P_{\text {req_ref }}$ and $Q_{\text {req_ref }}$ that requested by grid and/or isolated loads. These reference powers are calculated by using the powers generated by hybrid renewable energy system and by considering the power in the capacitor for regulation of DC link voltage $U_{c}$ and losses in the electronic converters.

The PWM signals are determined by using SVM method to drive the six inverter IGBT's of inverter. They generate the real inverter output voltages from their reference values calculated by the sliding mode controller and transfer the necessary active and reactive powers to the alternative side. Figure 2 shows the control strategy of a three-phase-inverter for HRES.

\section{A. DC-Link Voltage Control}

The main aim of the voltage control loop is to regulate the DC-link voltage at a specified value and to provide the reference current. The DC-link voltage is set to $515 \mathrm{~V}$ while the grid line voltage $\left(\mathrm{V}_{\mathrm{rms}}\right)$ is set to $220 \mathrm{~V}$. The closed loop control of the DC-bus voltage is needed because the output power of the renewable sources is variable with climatic conditions. The inverter input reference current $\mathrm{i}_{\mathrm{e} \text {-ref }}$ is described by the following relation: $i_{e-r e f}=i_{d c}-P I\left(U_{c-r e f}-U_{c}\right)$

For the control of the DC-link voltage, a proportional integral corrector (PI) has been used. It is parameterized according to the capacitor and the dynamic of the regulation loop. By neglecting losses in the inverter switcher, the power balancing yields:

$P_{\text {req }} \approx i_{e} \cdot U_{c}$ by:

The reference active power injected into the grid is given

$P_{\text {req_ref }} \approx i_{e-r e f} \cdot U_{c}$

\section{B. Sliding Mode Control of 3-Phase Inverter}

The sliding controller requires the knowing of the sliding surface, the condition of convergence and the control law. The general form of the sliding surface is given in[12]:

$$
\mathrm{S}(\mathrm{x})=\left(\frac{\partial}{\partial \mathrm{t}}+\lambda_{\mathrm{x}}\right)^{\mathrm{r}-1} \mathrm{e}(\mathrm{x})
$$

With:

$\mathrm{e}(\mathrm{x})=\mathrm{x}_{\mathrm{ref}}-\mathrm{x}$, is the error of the variable to be regulated

$\lambda_{x}$ is a positive constant which interprets the band-width of the desired control.

$r$ : is a number of times that it is necessary to derive the output variables to reveal the command.

$\mathrm{S}(\mathrm{X})=0$ : A linear differential equation whose single solution is $\mathrm{e}(\mathrm{x})=0$.

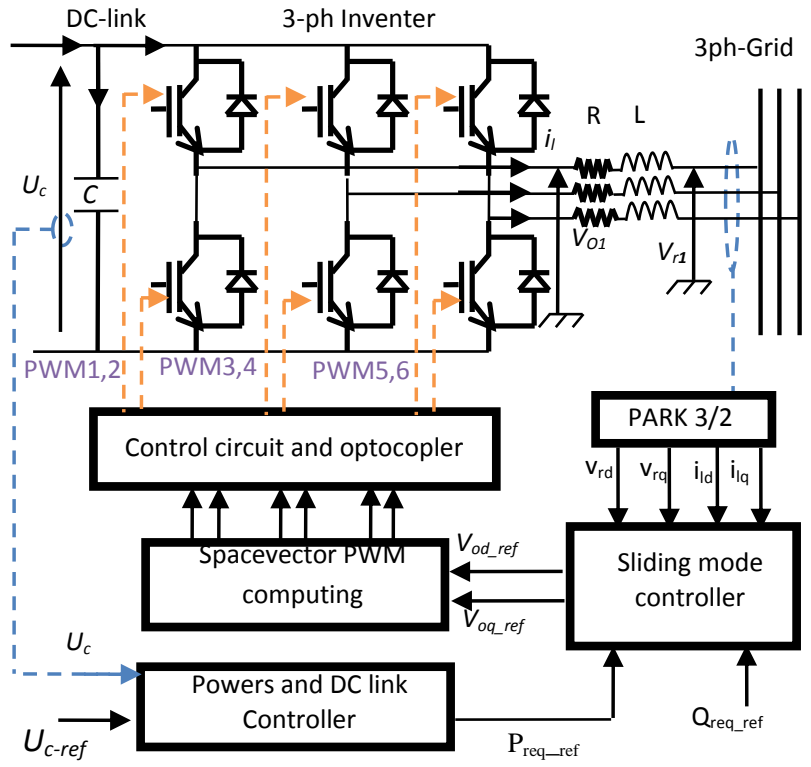

Fig. 2. Control Strategy Diagram.

The general form of the sliding controller is $\mathrm{U}=\mathrm{U}_{\mathrm{eq}}+\mathrm{U}_{\mathrm{nl}}$. $U_{e q}$ and $U_{n l}$ are respectively the equivalent controller that is the solution of the equation $\dot{S}(X)=\mathrm{O}$ and the nonlinear part 
that can be interpreted as the overage value of the controller which permits to maintain the state of the system on the sliding surface $[13,14]$. The nonlinear command $\left(U_{n l}\right)$ is given to guarantee the attractively of the variable to be controlled towards the sliding surface and to satisfy the condition of convergence. The simplest function is in the form of relay. It is given by $\mathrm{U}_{\mathrm{nl}}=\mathrm{K}$. $\operatorname{sign}(\mathrm{S}(\mathrm{X}))$ with $K$ is a positive constant $[13,14]$.

\section{Application to the inverter}

The control vector is carried out by the model of the RLline filter. This model is given, in Park dq- axis, by:

$$
\left\{\begin{array}{l}
V_{O d}=R i_{l d}+L \frac{d i_{l d}}{i_{l d}}-L \omega_{s} i_{l q}+V_{r d} \\
V_{O q}=R i_{l q}+L \frac{d i_{l q}}{i_{l q}}+L \omega_{s} i_{l d}+V_{r q}
\end{array}\right.
$$

With $V_{o d}$ and $V_{o q}$ are the inverter output voltages in $d q$ axis ; $V_{r d}$ and $V_{r q}$ are the grid voltages in $d q$-axis ; $R$ and $L$ are respectively the resistance and the inductance of the filter; $\omega_{s}$ is the frequency of injected currents. The control vector $U=\left[\begin{array}{ll}V_{o d_{-} r e f} & V_{o q_{-} r e f}\end{array}\right]^{T}$ is given by the direct inversing of Eq. 5. It's expressed as follows:

$\left\{\begin{array}{l}V_{o d_{-} r e f}=V_{l d_{-} r e f}-L \omega_{s} i_{l q}+V_{r d} \\ V_{\text {oq_ref }}=V_{l q_{-} r e f}+L \omega_{s} i_{l d}+V_{r q}\end{array}\right.$

The output is the currents vector $I_{l}=\left[\begin{array}{ll}i_{l d} & i_{l q}\end{array}\right]^{T} . \mathrm{S}_{1}$ and $\mathrm{S}_{2}$ constitute respectively the sliding surfaces of the exit variables $i_{l d}$ and $i_{l q}$. They represent the errors of the direct and quadratic currents. They are expressed as follows:

$$
\left\{\begin{array}{l}
S_{1}=I_{l d_{-} r e f}-i_{l d} \\
S_{2}=I_{l q_{-} r e f}-i_{l q}
\end{array}\right.
$$

By using the equations of system (6), the first derivation of Eq. 7 gives:

$$
\left\{\begin{array}{l}
\dot{S}_{1}=\dot{I}_{l d_{-} r e f}+\frac{1}{L}\left[R i_{l d}-L \omega_{s} i_{l q}+V_{r d}\right]-\frac{1}{L} V_{o d} \\
\dot{S} 2=\dot{I}_{l q_{-} r e f}+\frac{1}{L}\left[R i_{l q}+L \omega_{s} i_{l d}+V_{r q}\right]-\frac{1}{L} V_{o q}
\end{array}\right.
$$

The relative degree of the system is equal to 1 because the command appears in the first derivation of the variables to be controlled. Equation 8 can be replaced by:

$$
\left\{\begin{array}{l}
\dot{S}_{1}=B_{1}+A_{1} V_{l d} \\
\dot{S}_{2}=B_{2}+A_{2} V_{l q}
\end{array}\right.
$$

With :
$\left\{\begin{array}{l}B_{1}=\dot{I}_{l d_{-} r e f}+\frac{1}{L}\left[R i_{l d}-L \omega_{s} i_{l q}+V_{r d}\right] \\ A_{1}=-\frac{1}{L} \\ B_{2}=\dot{I}_{l q_{-} r e f}+\frac{1}{L}\left[R i_{l q}+L \omega_{s} i_{l d}+V_{r q}\right] \\ A_{2}=-\frac{1}{L}\end{array}\right.$

The solution of equation $\dot{S}=0$ leads to the equivalent controller $\left(\mathrm{U}_{\mathrm{eq}}\right)$. Its expression is given by:

$\left\{\begin{array}{l}V_{l d_{-} e q}=-\frac{B_{1}}{A_{1}} \\ V_{l q_{-} e q}=-\frac{B_{2}}{A_{2}}\end{array}\right.$

The nonlinear part of the sliding controller is given by:

$\left\{\begin{array}{l}V_{l d_{-} n l}=K_{d} \operatorname{sign} S_{1} \\ V_{l q_{-} n l}=K_{q} \operatorname{signS}_{2}\end{array}\right.$

With:

$\mathrm{K}_{\mathrm{d}}=\mathrm{K}_{\mathrm{q}}=\mathrm{K}=\left|\mathrm{V}_{\max }\right|$.

The global command $U=\left[\begin{array}{ll}V_{\text {od_ref }} & V_{o q_{-} r e f}\end{array}\right]^{T}$ is the sum of the equivalent and the nonlinear parts given by equations 11 and 12. It's expressed as follows:

$\left\{\begin{array}{l}V_{\text {od_ref }_{\text {ref }}}=L \dot{I}_{l_{d_{-} r e f}}+R i_{l d}-L w_{s} i_{l q}+V_{r d}+K_{d} \operatorname{sign} S_{1} \\ V_{\text {oq_ref }}=L \dot{I}_{l q_{-} r e f}+R i_{l q}+L w_{s} i_{l d}+V_{r q}+K_{q} \operatorname{signS} S_{2}\end{array}\right.$

The reference currents, given in 13, are expressed as functions of the active and reactive reference powers requested by the grid and / or isolated loads. They are given by:

$\left\{\begin{array}{l}I_{l d_{-} r e f}=\frac{P_{r e q_{-} r e f} \cdot V_{r d}+Q_{r e q_{-} r e f} \cdot V_{r q}}{V_{r d}^{2}+V_{r q}^{2}} \\ I_{l_{q_{-} r e f}}=\frac{P_{r e q_{-} r e f} \cdot V_{r q}-Q_{r e q_{-} r e f} \cdot V_{r d}}{V_{r d}^{2}+V_{r q}^{2}}\end{array}\right.$

\section{Three-Phase Inverter SVPWM}

The SVPWM (Fig.3) is a technique used to drive the inverter switches to generate equilibrate three-phase voltages with desired amplitude and frequency; $V_{o a}, V_{o b}$ and $V_{o c}$, from the reference voltages $V_{o a_{2} r e f}, V_{o b_{2} r e f}$ and $V_{o c_{-} r e f}$. These voltages are calculated by the Park transformation (dq-abc) of the inverter voltages $V_{\text {od_ref, }} V_{\text {oq_ref }}$ provided by the sliding controller bloc $[15,16]$.

As indicated by figure 4 , the algorithm of SVPWM is based on the knowledge of the reference vector $\overrightarrow{V_{\text {ref }}}$ which rotates in six sectors in the switching hexagon. Its coordinates are the components $V_{\alpha r e f}$ and $V_{\beta r e f}$, and the change values for each angle $\theta_{s}$ which allowing the calculation of the switching times. 


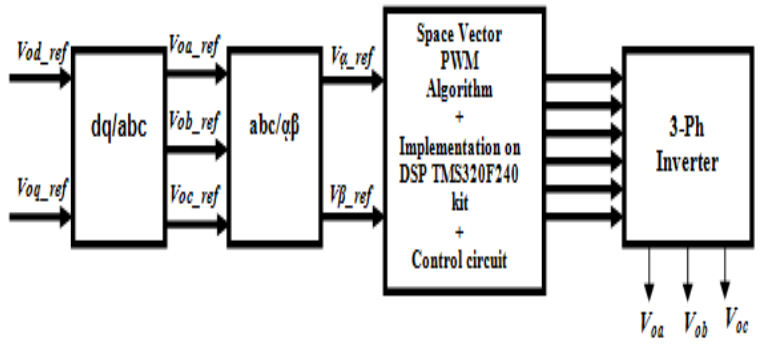

Fig. 3. SVPWM Signals Generation.

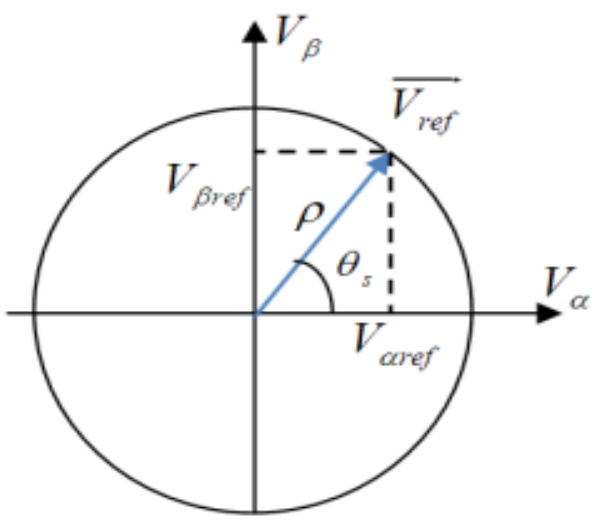

Fig. 4. Reference Vector Variation in $\alpha \beta$-axis.

- Amplitude Variation of Output Voltages

The components $V_{\alpha r e f}$ and $V_{\beta r e f}$ are expressed as follows:

$\left\{V_{\text {aref }}=\rho \cos \theta_{s}\right.$

$\left\{V_{\beta r e f}=\rho \sin \theta_{s}\right.$

The maximum radius of the circle within the switching polygon is $\rho_{\max }=\sqrt{\frac{3}{2}} V_{\max }=\frac{1}{\sqrt{2}} U_{c}$.

The 3-phase inverter controlled by SVPWM can generate three phase- voltages with maximum value equal to $\frac{U_{c}}{\sqrt{3}}$. Therefore, by selecting the variable $\rho$, we can set the amplitude of the inverter output signals.

\section{- Frequency Variation of Output Voltages}

The discretization of the reference vector requires a good choice of the number of samples per revolution, and therefore the sampling period on which to build it. The maximum number of samples per period is limited by the speed of calculation of the DSP TMS320F240.In general, for a number faster than $72\left(5^{\circ}\right.$ for a sample) the reference vector is continuously variable over time. To fix the period of the reference vector and the period of the inverter output voltages, it is necessary to fix the modulation period given by [17]:

$T_{m}=2 . T_{e} \cdot \frac{n}{F_{h}}$

With
- Te is the period corresponds to the count number of the (T1CNT) of DSP (TMS320F240). It is used to compare the corresponding values to the inverter switching times.

- $F_{h}$ is the clock frequency of the DSP fixed at $20 \mathrm{MHz}$.

- $n$ is the clock frequency of the DSP divider.

- The period of the inverter output variables is given by:

$T=k T_{m}=2 k T_{e} \frac{n}{F_{h}}$

The frequency of the inverter three-phase output voltages is $50 \mathrm{~Hz}(\mathrm{~T}=0.02 \mathrm{~s})$. To set this frequency value the following parameters are selected:

- $\mathrm{k}=360$.

- $T_{e}=138$.

- $\mathrm{n}=4$.

Figure5 shows the IGBT driving signals $\mathrm{PWM}_{\mathrm{i}}$ for $\mathrm{i}=\{1$, $2 \ldots 6\}$.

\section{SiMULATION STUDY}

Simulations by Matlab-Simulink software were performed to test and verify the 3-phase inverter control presented and developed in the previous section and to study the output inverter voltages, the injected currents, and the active and reactive powers transferred from the hybrid renewable energy system to the grid.

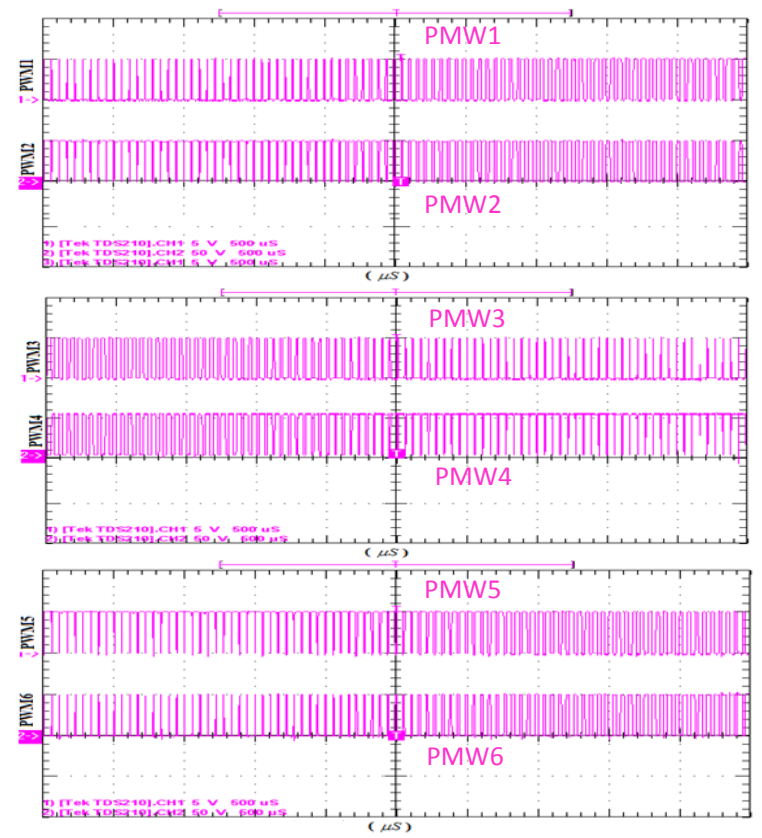

Fig. 5. Driving Signals.

These simulations have been obtained under various values of power requested by grid and/or loads. They are selected to demonstrate the most significant performances of the control approach. The reference and measure are respectively represented by dotted and continuous line. The interaction between the renewable energy sources is not 
discussed in this paper. Only the inverter control is considered in this paper.

\section{TABLE I. PARAMETERS OF THE GRID CONNECTED SYSTEM}

\begin{tabular}{|l|l|l|}
\hline value & symbols & Parameters \\
\hline $0.01 \mathrm{H}$ & $L$ & Inductance of the filter \\
\hline $0.92 \mu \mathrm{F}$ & $C$ & Capacitance of the DC-link \\
\hline $0.05 \Omega$ & $R$ & Resistance of the filter \\
\hline $314 \mathrm{rd} / \mathrm{s}$ & $w_{s}$ & Pulsation of the grid voltage \\
\hline $311 \mathrm{~V}$ & $K_{d}=K_{q}$ & Constant of the sliding control \\
\hline $515 \mathrm{~V}$ & $U_{\text {cref }}$ & DC-link voltage reference \\
\hline
\end{tabular}

A variable wind signal, shown on figure 6 , is applied to the turbines. It varied between 7 and $11 \mathrm{~m} / \mathrm{s}$ regarding the maximal power point tracking zone.

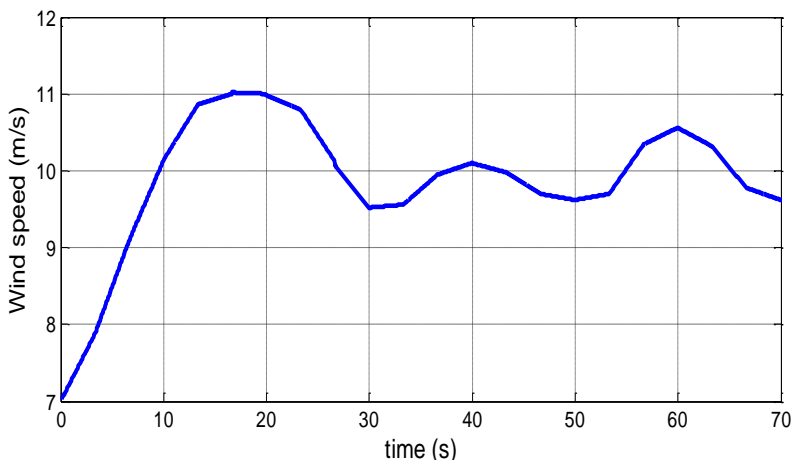

Fig. 6. Wind Speed Variation.

As indicated by figure 7 , the reference active power requested by the grid and/or loads $\left(P_{\text {req_ef }}\right)$ is considered variable within the time while the reference reactive power should be zero in order to obtain the line current in phase with the grid voltage. On figure $7 \mathrm{a}$, it is shown that the active power generated by the hybrid system satisfies the requested power however the reactive power transferred to the grid oscillates around its reference fixed at zero (Fig. 7b). According to those figures, the inverter output reactive power remains equal to zero while the active power varied with the demand of the load in the alternative side.

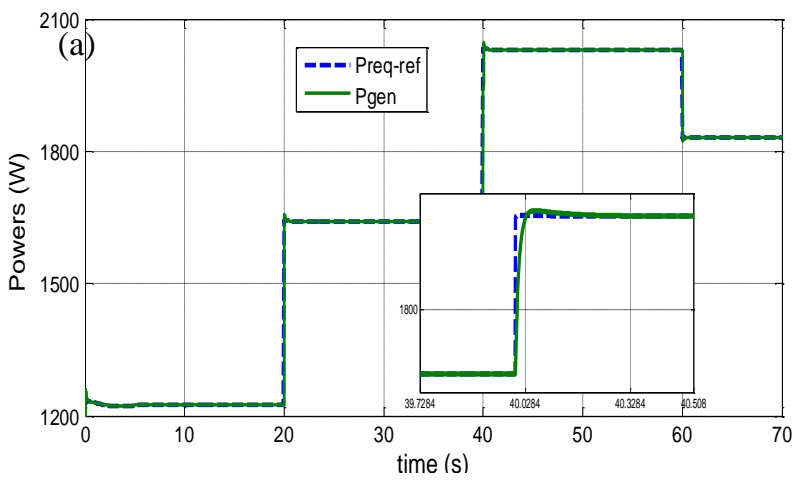

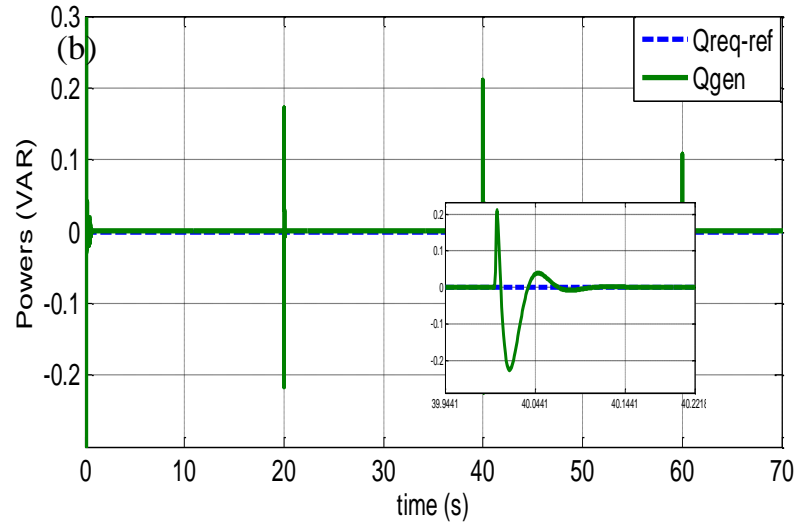

Fig. 7. Inverter output powers (measure and reference): (a): active powers, (b): reactive powers.

Figure $8 \mathrm{a}$ presents the DC-current provided by the renewable energy system to satisfy the power requested by the load. The current varied proportionally with the power values injected into the alternative side while the DC-link voltage is constant and follows its reference $\left(\mathrm{U}_{\mathrm{c}_{\text {_ref }}}\right)$ fixed at $515 \mathrm{~V}$. The DC-link voltage presents some instantaneously overshoots in each change of requested power load (Fig. 8b).
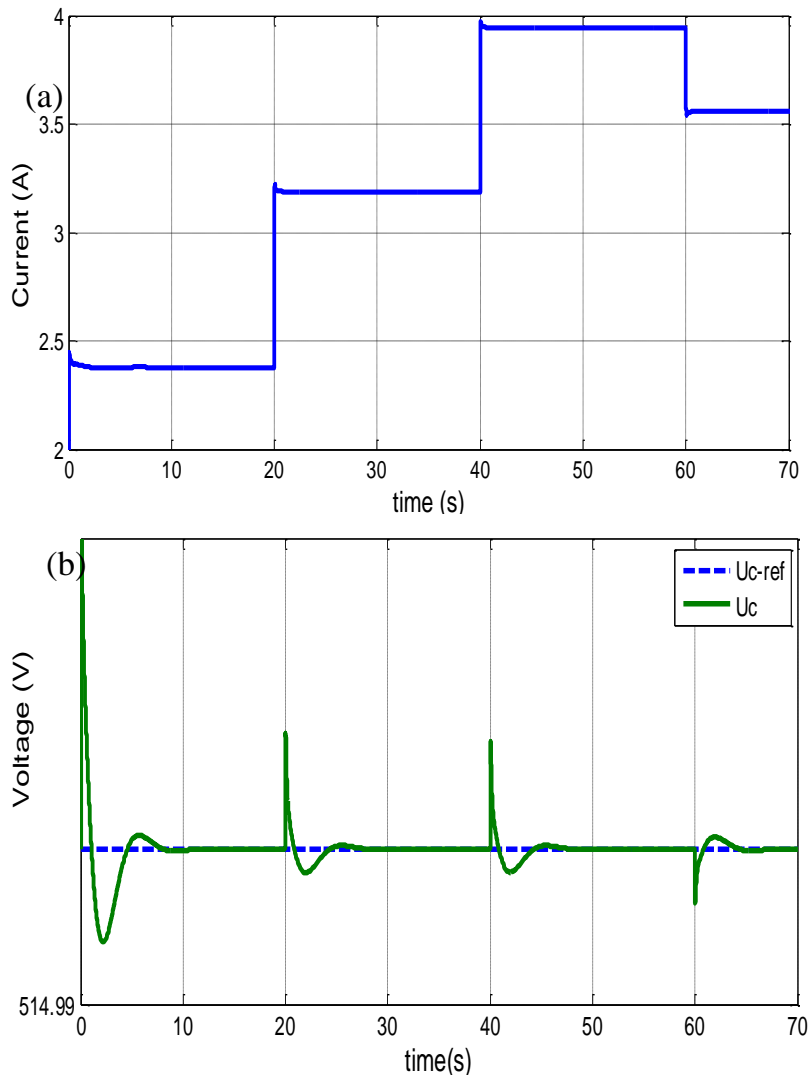

Fig. 8. Input characteristics of the inverter; (a): DC-current provided by the renewable energy system, (b): DC-link voltage (measure and reference). 

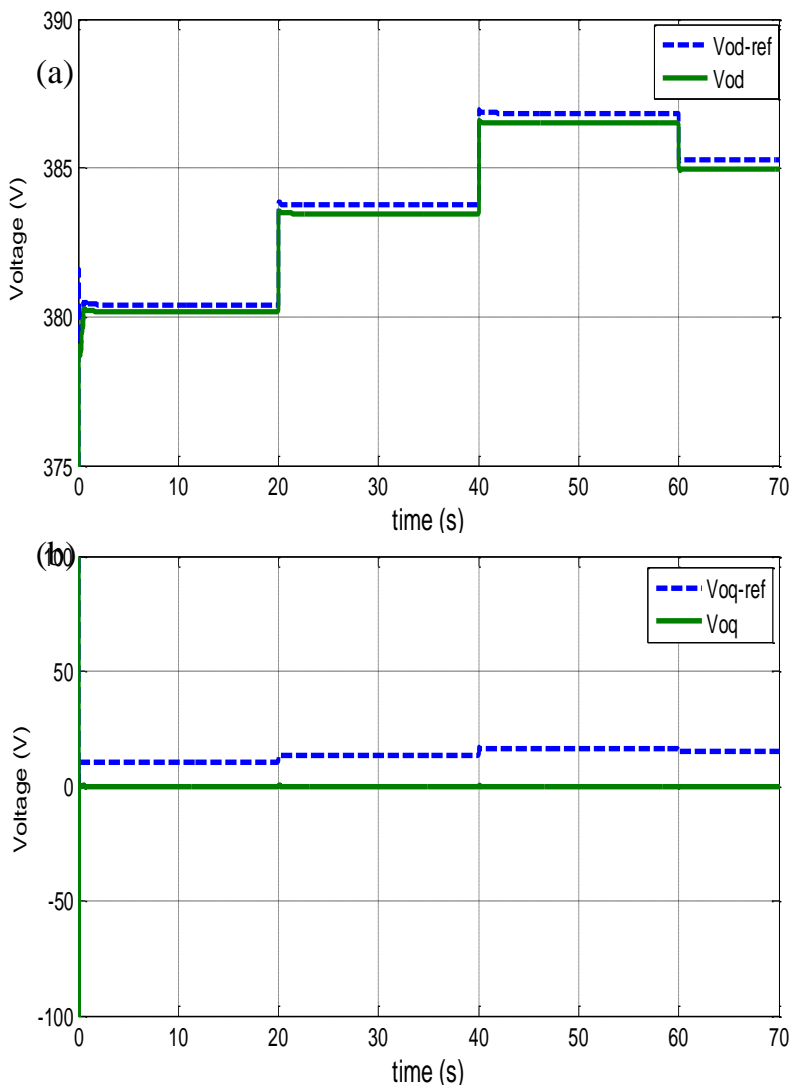

Fig. 9. Inverter output voltage (measures and references); (a): direct components; (b): quadratic components.

Figure 9 illustrates the dq-components of the inverter output voltage under variable load powers. As it can be seen by this figure, the sliding mode controller presents good performances in terms of stability and response time. The inverter output voltages reach instantaneously their reference values provided by the controller within the changes of the requested load power. The direct and the quadratic components of the inverter output current $i_{l d q}$ are represented respectively by figures $10 \mathrm{a}$ and $10 \mathrm{~b}$. As it can be seen by those figures, the inverter output currents reach instantaneously their reference values provided by the sliding controller.

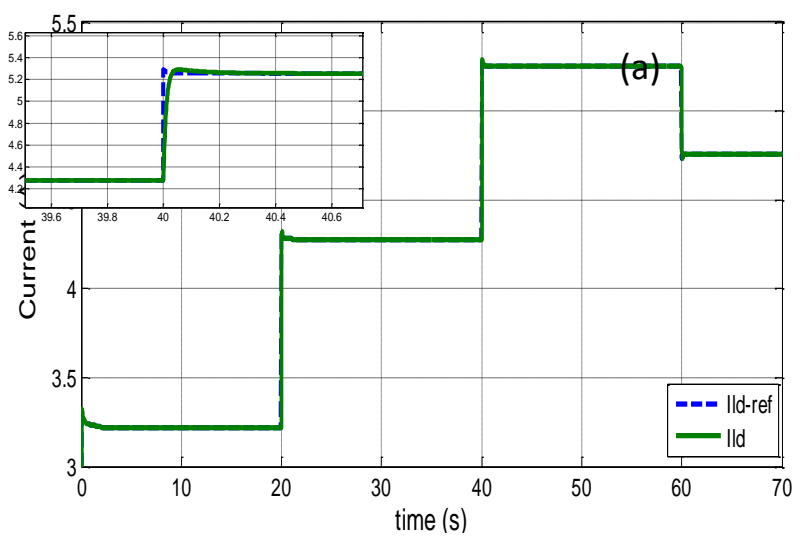

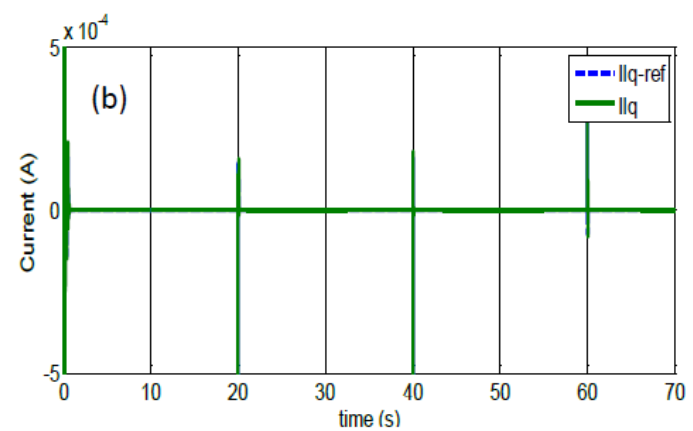

Fig. 10. Iinverter output current (measures and references); (a): direct components; (b): quadratic components.

Finally, the control unit composed by the sliding controller, the DC-link voltage regulator and the SVPWM block, achieves the control of the 3-phase grid connected inverter of hybrid renewable energy system. It permits to regulate instantaneously, the DC-link voltage, the inverter output powers (active and reactive powers) and the currents injected into the grid. The previously figures show the reliability and the short time response of the global system with the developed controller, even with the wind system that is very fluctuating and the diesel generator which has a very slow dynamics since it is a mechanical system.

\section{CONCLUSION}

In this paper, a control strategy based sliding mode controller, has been proposed. The command approach ensures the control of the 3-phase inverter output currents which leads the control of the active and reactive powers transferred into the grid and/or the isolated loads. In series with the sliding controller a SVPWM was developed to drive the six inverter switches to generate 3-phase voltages necessary to transfer the desired powers. This command approach (sliding controller with SVPWM) has given very acceptable results in terms of response time and accuracy of the controlled variables, especially since this system is very variable and has disturbances according to the wind speed.

\section{ACKNOWLEDGMENT}

This work is part of the project "Projets Jeunes chercheurs" funded by the Tunisian Ministry of High Education and Scientific Research. The support of the ministry is kindly acknowledged.

\section{REFERENCES}

[1] E. Gosden, "Global renewable power capacity overtakes coal as 500,000 solar panels installed every day", The Telegraph, London,2016.

[2] S. Younsi, M. Jraidi, N. Hamrouni and A.Cherif, "Modelling and control of hybrid renewable energy system connected to AC grid", International journal of computer sciences and engineering (IJCSE), Vol. 3 No. 12, 2011.

[3] S. Younsi, M. Jraidi, N. Hamrouni and A. Cherif, "Artificial neural network control of hybrid renewable energy system connected to AC grid", International journal of computational intelligence technique (IJCIT) Vol. 2, no. 2, pp. 44-52, 2011.

[4] S. Younsi, M. Jraidi and A. Cherif, "Modelling and control of wind farm associated with a flywheel energy storage system and a diesel generator connected to the network", Journées Tunisiennes d'Electrotechnique et d'Automatique (JTEA'2010), 26-28 Mars, Tunisia, 2010. 
[5] S. El AIMANI, "Modélisation de différentes technologies d'éoliennes intégrées dans un réseau de moyen tension", Thèse de doctorat de l'école centrale de Lille, 2003.

[6] Gabriel-Octavian CIMUCA, "Système de stockage d'énergie associé à des générateurs éoliennes", Thèse de Doctorat de l'ENSAM, 2004.

[7] H. Ozbaki and M.Kesler, "Active and reactive power control of grid-tied three phase inverter for PV system", International journal of hydrogen energy, August 2016.

[8] M. Binh and M. T. Dat, "Active and reactive power controller of gridconnected single phase photovoltaic system", International journal of hydrogen energy.

[9] D. Rekioua and A. Y. Achour, "Tracking Power Photovoltaic system with sliding mode control strategy", Energy Procedia, Vol. 36, pp. 219230, 2013.

[10] F. Pires,"Dual-inverter for grid connected photovoltaic system: modeling and sliding control", solar energy, vol. 86, no. 7, pp. 21062115, 2012.

[11] H. Amimeur and D. Aouzelleg, "Sliding Mode Control of a dual-Stator induction generator for wind energy conversion systems", International Journal of Electrical Power \& Energy Systems.vol. 42 no. 1, pp. 60-70, 2012.

[12] V.I. Utkin, " Sliding mode in control optimization", springer-verlag, Berlin 1992.

[13] H. Buhler, "Réglage par mode de glissement", presse polytechnique romande, 1986

[14] V.I. Utkin, "Sliding mode control design principles and application to electric drives", IEEE Trans on Elect, vol. 40 pp. 23-36, 1993.
[15] H. djaghloud and H. Benallah, "Space Vector Pulse Width Modulation Applied to Three-level Voltage Inverter", 5th International Conference on Technology and Automation ICTA'05, Thessaloniki, Grece Oct. 2010.

[16] J. H. Seo, C. H. Choi and D. S. Hyun " A new Simplified Space Vector PWM Method for Three-level Inverter " IEEE Transactions on Power Electronics, vol. 16, no. 4, pp. 545- 550, 2010.

[17] K.B. Priya, J. B. V. Subrahmanyam, C. Sikanth and M. Ayoub, "Space vector PWM Technique for 3phase voltage source inverter using Artificial Neural Network", International Journal of Engineering and Innovative Technology, Vol. 1, 2012.

\section{AUTHOR'S PROFILE}

Nejib Hamrouni received his engineering degree from the National Engineering School of Sfax, in 2000 and the PHD from the National Engineering School of Tunis, in 2009, both in electrical engineering. $\mathrm{He}$ is an Assistant professor at National Engineering School of Gabés from 2010 to 2015. Since September 2015 he is an assistant professor at ISSAT of Mateur. He has participated in several research and cooperation projects, and is the author of more than 20 international communications and publications.

Sami Younsi obtained his engineering degree from the National Engineering School of Sfax and his PHD in electrical engineering in 2013 from the Science Faculty of Tunis. He is an Assistant professor at the Institute of Technologies of Tunis. 